\title{
The Kanehira-Hatusima 1940 Collection of New Guinea Plants. V.
}

\author{
R. Kanehira \& S. Hatusima: Apocynaceae
}

Received October 9, 1941.

In this paper we propose to enumerate all the plants belonging to the Apocynaceae which were collected in the 1940 expedition. We actually secured 30 species representing 14 genera; two collections are sterile or too imperfect to study. In New Guinea, about eighty species are known representing 28 genera; thus our collection contains nearly one half of known Papuan species of the family. The Apocynaceae, so far as the localities we explored are concerned, is most abundantly represented at low altitudes the number of species diminishing at higher altitudes. Among the most prevailing genera of the family were Alyxia and Parsonsia, the former especially rich in high mountains and most of the species being endemic. As to growth-forms of the Apocynaceae, the liana and scandent shrubs were most predominant and no arboreous plants are represented except in Alstonia, Rejoua, Cerbera, Ochrosia, Lepiniopsis, Voacanga and Rauwolfia, these being medium-sized or small tree. Of the useful plants, the bark of Ichnocarpus frutescens and Alstonia scholaris are utilized by the Papuans, the former being called "Pipisa" and the latter "Ditain".

We must thank Dr. E. D. MerRILL for assistance in checking our identifications and giving us many important suggestions. The cost of this research has been defrayed from the Scientific Research Expenditure of the Department of Education.

Alstonia scholaris (Linn.) R. BR. in Mem. Wern. Nat. Hist. Soc. 1 (1811) 76; K .Schum. et Lautb. Fl. Deutsch. Schutzg. Südsee (1901) 501; Markgf. in Engl. Bot. Jahrb. 61 (1927) 177.

No. 13275 Kanehira-Hatusima, Momi, March 3, 1940. Fairly common in rain forests at low altitudes. A very large tree, $2 \mathrm{~m}$. in diameter, $30 \mathrm{~m}$. in height.

Distrib. India through Malaya to the Philippines and northern Australia.

Alyxia arfakensis Kanehira et Hatusima sp. nov. Fig. 1.

Frutex scandens vel erectus, ramis subtriquetris griseis, ramulis triquetris, circ. $2 \mathrm{~mm}$. crassis, ternatim verticillatis, glabris, verruculosis; 


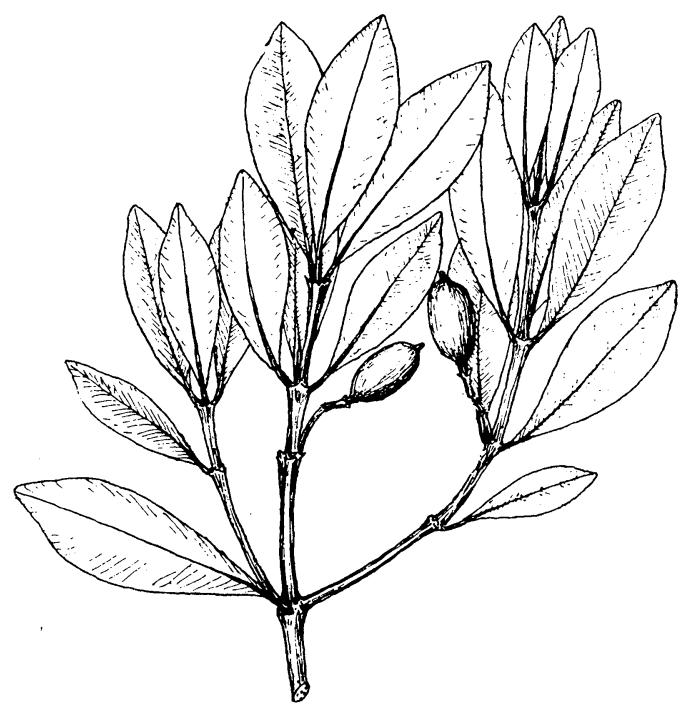

Fig. 1. Alyxia arfakensis KANEH. et HATUS. (no. 13717) $\times 2 / 3$.

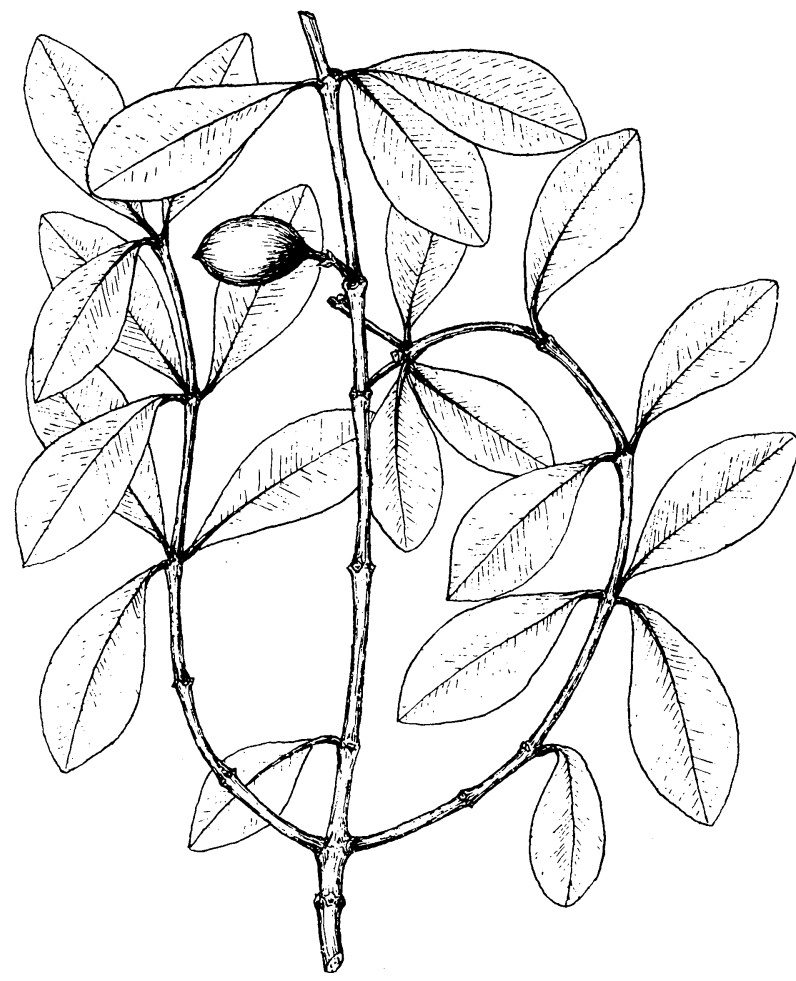

Fig. 2. Alyxia punctata KaneH. et Hatus. (no. 13466) $\times 2 / 3$. internodiis $1.5-2 \mathrm{~cm}$. longis. Folia petiolata ternatim verticillata, inter se subaequalia, firme coriacea, glabra, oblanceolata vel anguste obovata, circ. 2-4 cm. longa (plerumque $3 \mathrm{~cm}.), \quad 0.5-1 \mathrm{~cm}$. lata (plerumque $1 \mathrm{~cm}$.), apice breviter obtuse acuminata vel obtuse acuta, basi angustata glabra, margine leviter anguste recurvata, costa media supra valde impressa, subtus elevata, nervis lateralibus supra leviter elevatis, subtus obsoletis ; petiolo 3-5 $\mathrm{mm}$. longo, glabro. Flores ignoti. Infructescentiae axillares, bifurcatae, 1$1.5 \mathrm{~cm}$. longae, mericarpiorum articulo 1 , ellipsoideo, $1-1.3 \mathrm{~cm}$. longo, $7 \mathrm{~mm}$. crasso, apice apiculato, stipite 1-1.5 mm. longo ; pedunculo verruculoso, 5-7 mm. longo, $1 \mathrm{~mm}$. crasso, pedicello circ. $3 \mathrm{~mm}$. longo, $0.8 \mathrm{~mm}$. crasso. Lobi calycis sub fructu ang'uste triangulares, apice acuti, margine ciliati, extus glabri, circ. $1 \mathrm{~mm}$. longi.

No. 13717 KANEhira-Hatusima, Angi, Arfak Mts., April 6, 1940. Iu spinneys on the open summit of 
Mt. Koebre at 2,300 m. altitude. A scandent shrub, about $1 \mathrm{~m}$. high. This may be contrasted with Alyxia semipallescens F. v. MüLL. from southeastern New Guinea.

Alyxia pugio MarkgF. in ENGL. Bot. Jahrb. 61 (1927) 182.

Ad descriptionem addenda; Mericarpia 1-2, ellipsoidea circ. $1.3 \mathrm{~cm}$. longa, $1 \mathrm{~cm}$. lata, glabra.

No. 12307 (fl.), No. 12304 (fr.) Kanehira-Hatusim.a, Dallmann, March 1, 1940. In Agathis-forests at about $500 \mathrm{~m}$. altitude. A scandent shrub.

Distrib. North-eastern New Guinea.

Alyxia punctata Kanehira et Hatusima sp. nov. Fig. 2.

Frutex scandens, ramis cinerascentibus, ramulis gracilibus, 1-2 mm. crassis, subtriquetris, junioribus primo sparse pilosulis mox glabris, internodiis circ. $2 \mathrm{~cm}$. longis. Folia ternatim verticillata, coriacea, elliptica vel obovato-elliptica, $2-4 \mathrm{~cm}$. longa, $1.2-2 \mathrm{~cm}$. lata, apice obtusa, basi cuneata, supra primo in parte inferiore sparse pilosula demum glabra, nitidula, subtus opaca dense fuscescenti-punctata, nervis lateralibus utrinque obsoletis, costa media supra leviter, subtus vix elevata, petiolo $3-5 \mathrm{~mm}$. longo, 1-1.3 mm. crasso, supra sulcato primo sparse albidopilosulo. Flores ignoti. Infructescentiae axillares circ. $1 \mathrm{~cm}$. longae, pauce ramosae, pedunculo circ. $6 \mathrm{~mm}$. longo, $1 \mathrm{~mm}$. crasso, dense puberulo, pedicello circ. $5 \mathrm{~mm}$. longo, $1 \mathrm{~mm}$. crasso, puberulo. Mericarpiorum articulus 1, ellipsoideus, circ. 1.5 cm. longus. $1 \mathrm{~cm}$. latus, apice basique albo-pilosulus, stipite $2 \mathrm{~mm}$. longo, $1 \mathrm{~mm}$. crasso. Lobi calycis sub fructu ovati, apice obtuse acuti, circ. $1 \mathrm{~mm}$. longi, margine ciliolati, extus pilosuli.

No. 13717a Kanehira-Hatusima, Angi, Arfak Mts., April 6, 1940. In spinneys on the summit of Mt. Koebre at 2,400 m. altitude.

The species is well characterized by its small elliptic obscurely nerved leaves densely punctate beneath and also by its large fruits pilose at both ends which indicate pubescent ovaries. The plant may be referable to Alyxia subalpina MarkgF.

Alyxia purpureoclada Kanehira et Hatusima sp. nov. Fig. 3.

Frutex scandens glaber, ramulis subtriquetris, $2-3 \mathrm{~mm}$. crassis, glabris, purpurascentibus, lucidusculis, lenticellis cinerascentibus sparse obtectis. Folia ternatim verticillata, oblongo-oblanceolata, apice breviter obtuse acuminata vel obtuse cuspidata, basi sensim angustata, 5-10 cm. longa, $1.5-3 \mathrm{~cm}$. lata, coriacea, utrinque nitidula, concoloria, nervis lateralibus numerosis, parallelibus, utrinque distintis, petiolo 5-10 mm. longo, 1-1.5 mm. 
crasso. Inflorescentiae axillares, paniculatae, eirc. $3 \mathrm{~cm}$. longae, $2 \mathrm{~cm}$. latae, pedunculo 1-1.5 $\mathrm{mm}$. longo, $1 \mathrm{~mm}$. crasso, bracteolae membranaceae, navi-

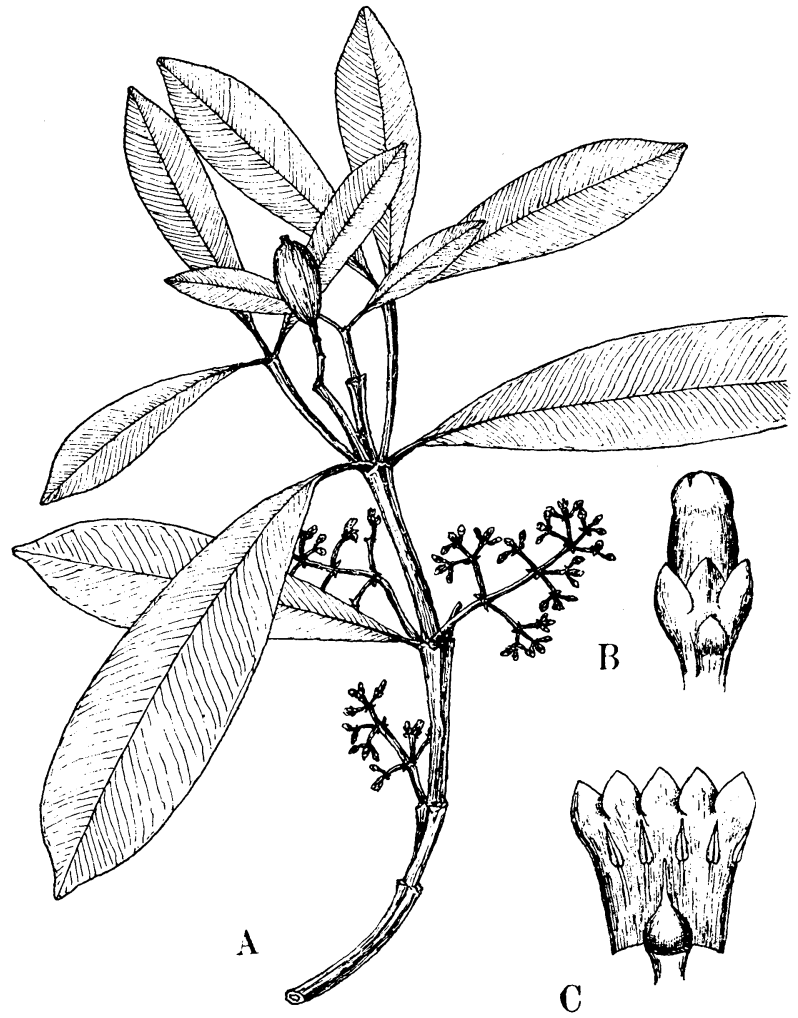

Fig. 3. Alyxia purpureoclada KaneH. et Hatus. $\times 2 / 3$.

A Branchlet with flowers and fruit

B Flower $\times 5$. C Corolla expanded $\times 7$. culares, circ. $0.8 \mathrm{~mm}$. longae, glabrae; flores glomerati, parvi, subsessiles. Calyx $1 \mathrm{~mm}$. longus, $1.5 \mathrm{~mm}$ latus, lobis ovatis, $0.7 \mathrm{~mm}$. longis, extus glabris, apice acutis. Tubus corollae cylindricus, circ. $2 \mathrm{~mm}$. longus, $1 \mathrm{~mm}$. latus, intus glaber, lobis late ovatis, circ. $0.6 \mathrm{~mm}$. longis. Stamina in tertia parte longitudinis tubi sub fauce inserta. Antherae longe apiculatae, circ. $1 \mathrm{~mm}$. longae, filamentis subduplo lóngiores. Mericarpiorum articulus 1 , ellipsoideus, cire. $1 \mathrm{~cm}$. longus, $6 \mathrm{~mm}$. crassus, glaber.

No. 13466 KANEhira-Hatusima, Angi, Arfak Mts., April 6, 1940. In spinneys on the summit of Mt. Koebre, at 2,400 m. altitude.

This is well characterized by its shining purpurascent branchlet ${ }^{\text {, large }}$ coriaceous leaves with numerous lateral nerves distinctly elevated on both surfaces, and by its very small subsessile flowers.

Alyxia Pullei Markgr. in Nova Guinea 14 (1926) 281 et Engl. Bot. Jahrb. 61 (1927) 186.

Ad descriptionem addenda: Mericarpia 2 vel 3, ellipsoidea, circ. 1.1 cm. longa, 7-8 mm. lata, glabra.

No. 13717 Kanehira-Hatusima Angi, Arfak Mts., April 6, 1940. In spinneys on the summit of Mt. Koebre at 2,400 m. altitude. An erect shrub. 
Distrib. Endemic.

Alyxia lata Markgf. in Engl. Bot. Jahrb. 61 (1927) 182.

No. 13325 Kanehira-Hatusima, Waren, 60 miles south of Manokwari, March 31, 1940. In strand forests, scandent.

Distrib. Kei Island. The type from Miosnom Island in Geelvink Bay.

Clitandropsis novo-guineensis (Wernh.) S. Moore ex MarkgF. in Nova Guinea 14 (1926) 279 ; EngL. Bot. Jahrb. 61 (1927) 174. Fig. 4.

Clitandropsis papuana S. Moore in Journ. Bot. 15 suppl. (1923) 31.

Willhghbeia novo-guineensis WernH. in Trans. Linn. Soc. London 2 ser. Bot. 9 (1916) 108.

No. 12772 Kanehira-Hatusima, Boemi, $40 \mathrm{~km}$. inward of Nabire, March 11, 1940. In primary forests at $400 \mathrm{~m}$. altitude. Scandent, flower yellowish.

Distrib. Endemic.

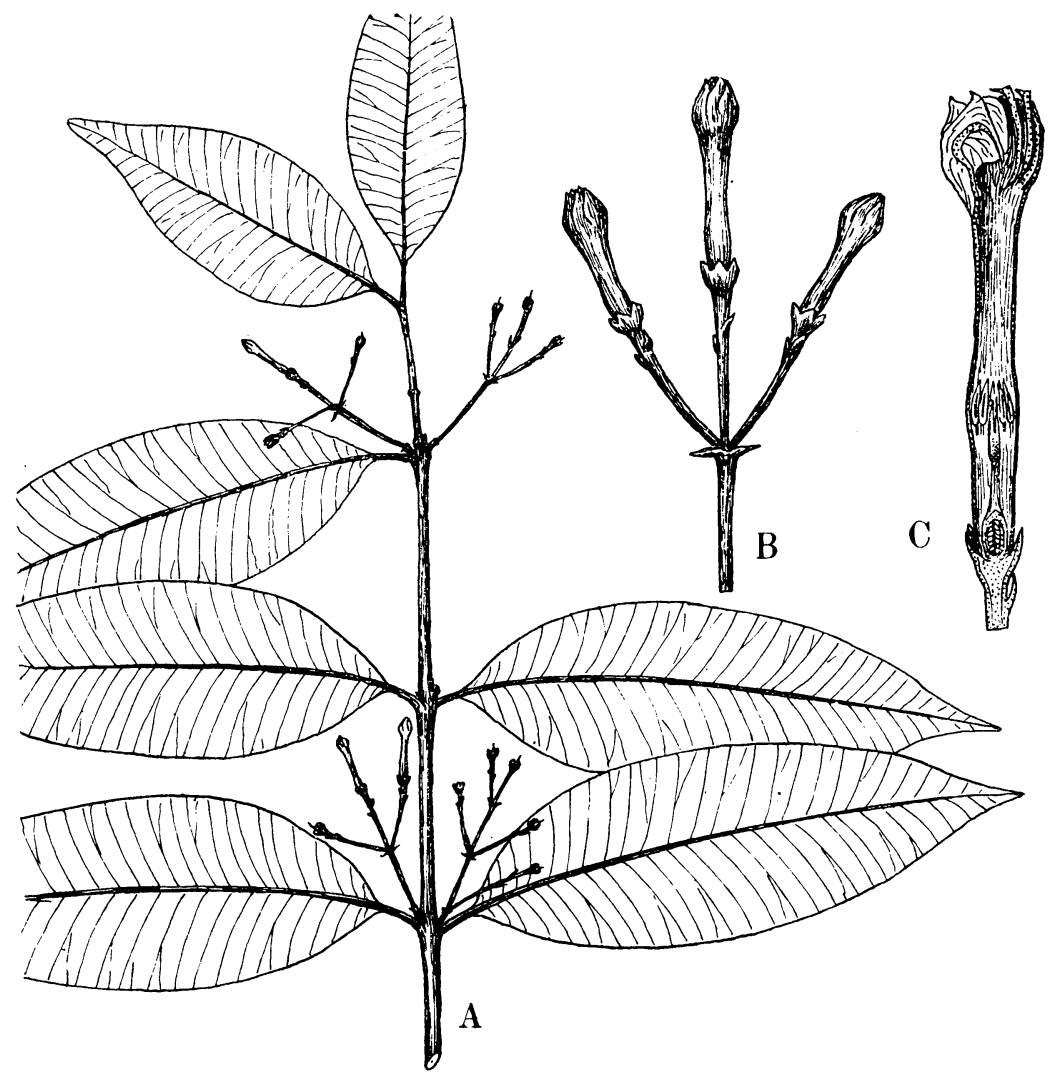

Fig. 4. Clitandropsis novo-guineensis S. Moore. (no. 12772)

A Branchlet with flowers $\times \frac{2}{3}$. B Inflorescence $\times 2$. C Flower in $1 . s$. 
Clitandropsis crassifolia Kanehira et Hatusima sp. nov. Fig. 5.

Frutex scandens, ramis teretibus, glabris, $2 \mathrm{~mm}$. crassis. Folia opposita, petiolata, glabra, coriacea, elliptica vel oblongo-elliptica, utrinque glabra, nitidula, apice breviter obtuse acuminata, basi attenuata, 4-7.5 cm. longa, 2-4 cm. lata, petiolo $3 \mathrm{~mm}$. longo, nervis lateralibus rectis, utrinsecus 13-15, sub angulo $70^{\circ}-85^{\circ}$ e costa divergentibus, subtus elevatis, distinctis. Inflorescentiae axillares, multiflorae, circ. $1 \mathrm{~cm}$. longae, bracteolae ovatae, circ. $1 \mathrm{~mm}$. longae, margine ciliolatae, pedicello $3-4 \mathrm{~mm}$. longo. Lobi calycis ovato-triangulares, apice obtuse acuti, margine fusco-ciliolati, eglandulosi, 1-1.2 mm. longi, $0.5 \mathrm{~mm}$. lati, cetera ignota. Bacca ellipsoidea, circ. $4 \mathrm{~cm}$.

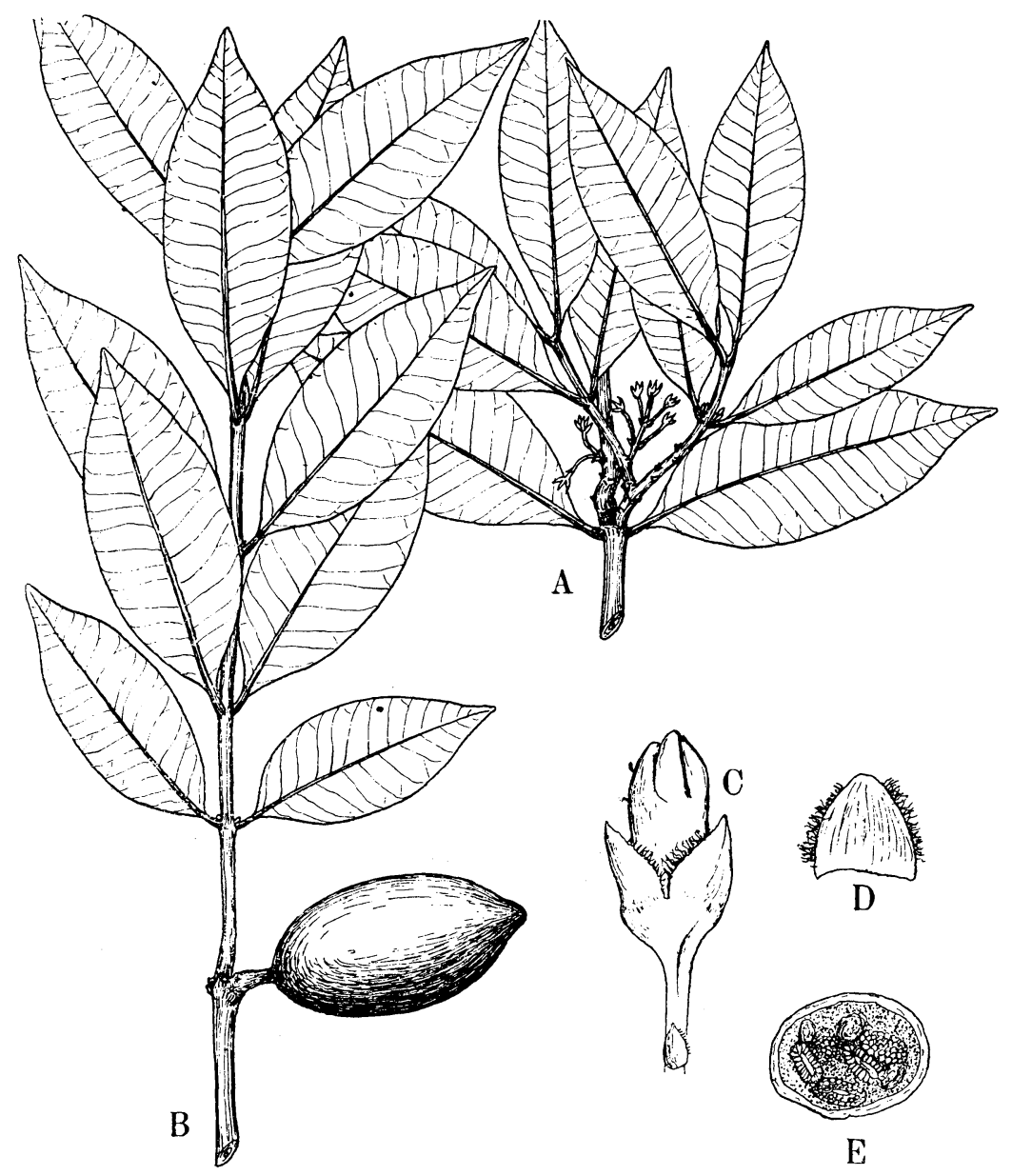

Fig. 5. Clitandropsis crassifolia KANEH. et Hatus. (no. 13749)

A Branchlet with flowers $\times 2 / 3$. B Branchlet with fruit.

C Flower. D Sepal. E Cross section of fruit. 
longa, $2 \mathrm{~cm}$. lata, intus pulpa repleta. Semina in pulpa nidulantia sparsa irregulariter subglobosa vel elliptica, plus minusve compressiuscula, supra rugosa, 7-8 $\mathrm{mm}$. longa, testa lignosa, $1 \mathrm{~mm}$. crassa.

No. 13749 Kanehira-Hatusima, Angi, Arfak Mts., April 7, 1940. In primary forests near Iray, Lake Angi Giji, at 1,900 m. altitude.

This interesting liana is closely related to the preceding species which has much thinner acuminate leaves, more slender branchlets, looser and longer panicles and much shorter calyx lobes. This may also be allied to Citandropsis insularis MARKG. which differs in its much larger leaves and globose fruits. The flowers of our material are young but there is no doubt as to the correctness of the generic identification.

Cerbera manghas Linn. Sp. Pl. (1753) 208; Markgr. in Engl. Bot. Jahrb. 61 (1927) 197.

No. 12856 Kanehira-Hatusima, Nabire, March 15, 1940. In strand forests.

Distrib. Tropical Asia through Malara to northern Australia and Polynesia.

Ervatamia eriophora MarkgF. in Nova Guinea 14 (1926) 286 ; Engl. Bot. Jahrb. 61 (1927) 200.

No. 11482 (fl.), No. 11472 (fr.) Kanehira-Hatusima, Nabire, Geelvink Bay, Feb. 24, 1940. On edge of dilluvial rain-forests at low altitudes. A shrub, $3 \mathrm{~m}$. high, flowers white.

Distrib. Endemic.

Ervatamia pubescens R. Br. var. punctulata (WARb.) MARKGE. in ENGL. Bot. Jahrb. 61 (1927) 199.

Ervatamia punctulata (WARB.) MarkgF. var. typica Markgr. in Nova Guinea 14 (1926) 285.

Tabernaemontana punctulata WARB. in ENGL. Bot. Jahrb. 13 (1891) 405.

Ervatamia montensis S. Moone in Journ. Bot. 51, Suppl. (1923) 32.

No. 13303 Kanehira-Hatusima, Waren, Momi, March 31, 1940. In secondary forests at low altitudes. A shrub, $2 \mathrm{~m}$. high, flowers greenish white.

Distrib. Southern New Guinea, Aru Islands, Kei Islands, northern Australia (var. eu-pubescens MARKGF.).

Ichnocarpus frutescens (Linn.) R. BR. in Mem. Wern. Soc. 1 (1809) 62; K. Schum. et Lautb. Fl. Deutsch Schutzg. Südsee (1901) 507 ; Markgf. in ENGL. Bot. Jahrb. 61 (1927) 207.

Apocynum frutescens Linn. Sp. Pl. (1753) 213. 
Ichnocarpus ovatifolius DC. Prodr. 8 (1844) 435.

Nos. 12881, 11739 Kanehira-Hatusima, Nabire, March 16, 1940 ; On edge of rain-forests at low altitudes. No. 12594 Kanemina-Hatusima, Sennen, $40 \mathrm{~km}$. inward of Nabire, March 8, 1940 ; in rain-forest fringe at about $400 \mathrm{~m}$. altitude, scandent.

Distrib. India through Malaya, Philippines to the Moluceas and Australia.

Lepiniopsis ternatensis VAL. in Amn. Jard. Bot. Buit. 12 (1895) 252, t. 28; Merr. Enum. Philip. Fl. Pl. 3 (1923) 321; Markgf. in Engl. Bot. Jahrb. 61 (1927) 172.

Lepiniopsis philippinensis Elm. in Leafl. Philip. Bot. 4 (1912) 1458.

Nos. 1300 (fr.), 13253 (fl.) Kanehira-Hatusima, Waren, Momi, March 21, 1940. In dilluvial rain-forests at low altitudes.

Distrib. Eastern New Guinea, Bismarck Archipelago, Moluccas and the Philippines.

Melodinus landolphioides K. Schum. et Lautb. Fl. Deutsch. Schutzg. Südsee (1901) 500; MarkgF. in Nova Guinea 14 (1926) 278; Engl. Bot. Jahrb. 61 (1927) 172.

Melodinus monogynus sensu S. Moore in Journ. Bot. 61, suppl. (1923) 31, non RoxB.

Neowollastonia tabernaemontanoides Wernh. ex RidLey in Hook. Icon. t. 3060 (1916), Trans. Linn. Soc. London 2 ser. Bot. 9 (1916) 110.

No. 12398 Kanehira-Hatusima, Patema, $40 \mathrm{~km}$. inward of Nabire, March 6, 1940. In rain-forest fringe, scandent.

Distrib. Southern New Guinea, Aru and Kei Islands.

Ochrosia ficifolia (S. Moore) Markgf. in Engl. Bot. Jahrb. 61 (1927) 190.

Alstonia ficifolia S. Moone in Journ. Bot. 61, Suppl. (1923) 32.

No. 11424 Kanehira-Hatusima, Nabire, Feb. 23, 1940. In edge of dilluvial rain-forests at low altitudes.

Distrib.

Ochrosia parviflora (Forst.) Henslow in Anm. Nat. Hist. 1 (1838) 345; MarkgF. in Nova Guinea 14 (1926) 283, Engl. Bot. Jahrb. 61 (1927) 191.

No. 13286 Kanehira-Hatusima, Waren, Momi, March 30, 1940. In strand forests.

Distrib. From western Malaysia to the Philippines and Micronesia.

Papuechites aambe (Warb.) Markgf. in Nova Guinea 14 (1926) 288; ENGL. Bot. Jahrb. 61 (1927) 209.

Anodendron aambe WARB. in ENGL. Bot. Jahrb. 13 (1891) 454. 
Ichnocarpus bertieroides WeRnH. ex S. MOORE in Journ. Bot. 51, Suppl. (1923) 33.

No. 12646 Kanehira-Hatusima, Slieber, $40 \mathrm{~km}$. inward of Nabire, March 9, 1940. In edge of forests at low altitudes.

Distrib. Endemic.

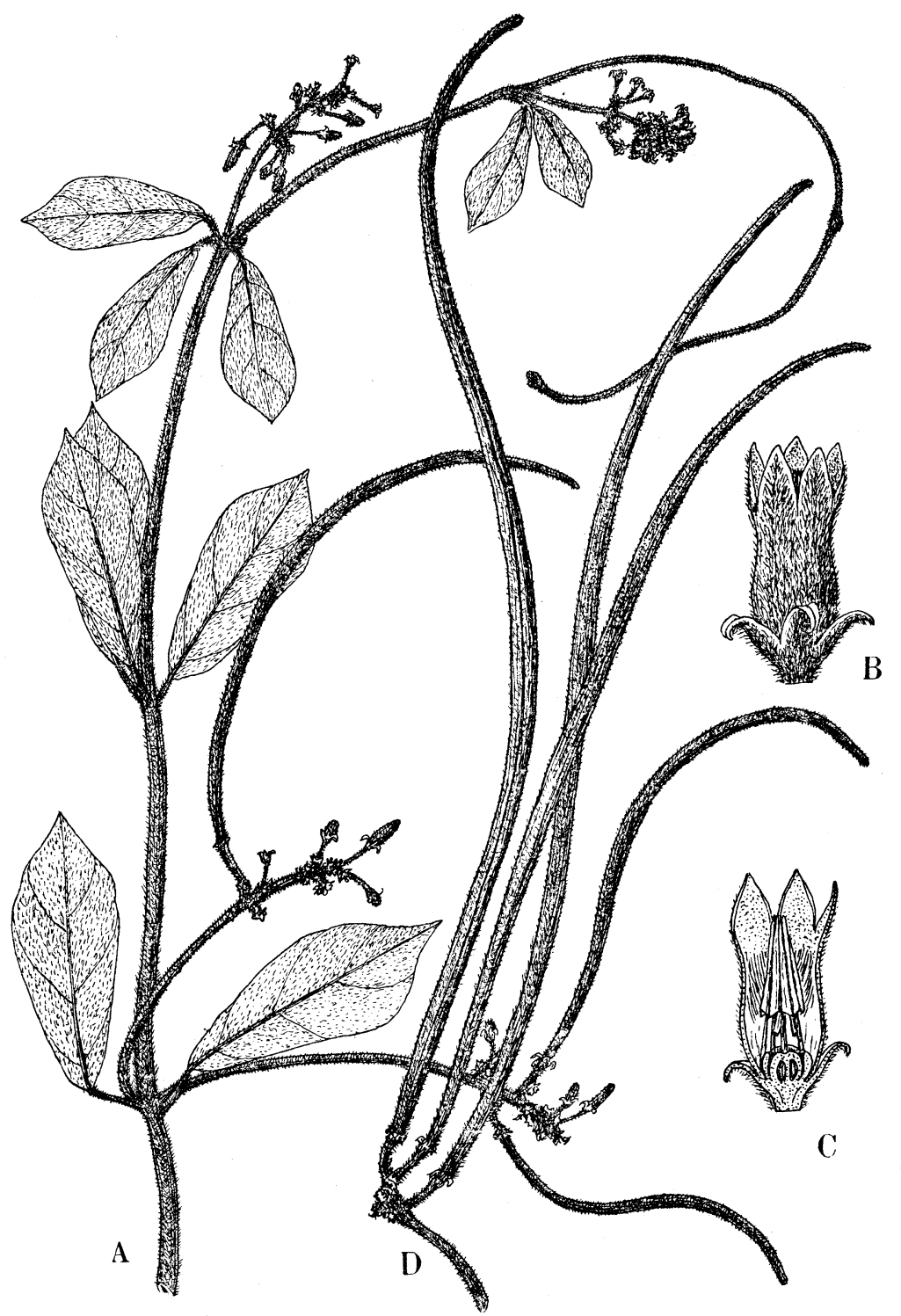

Fig. 6. Parsonsia dallmannensis KaneH. et Hat. (no. 12104)

A Branchlet with flowers. $\times 2 \% 3$. B Flower. C The same in 1. s. D Fruits. 
Parsonsia dallmannensis Kanehira et Hatusima sp. nov. Fig. 6.

Frutex scandens, ramis lignosis, fusco-cinerascentibus, circ. $3 \mathrm{~mm}$. crassis, glabrescentibus, ramulis junioribus dense fusco-pubescentibus, circ. $3 \mathrm{~mm}$. crassis. Folia ternatim verticillata rarius opposita, coriacea, obovatoelliptica vel late oblanceolata, 5-9 cm. longa, 1.5-5 cm. lata, apice breviter acuminata, basi obtuse acuta, margine leviter anguste revoluta, supra nitidia sparse adpresse hirsuta, subtus densiuscule fusco-hirsuta, opaca, costa media utrinque elevata, nervis lateralibus 4-5, plus minusve arcuatim adscendentibus, sub angulo $50^{\circ}$ a costa divergentibus, reticulatis, supra impressis, subtus elevatis ; petiolo $6-10 \mathrm{~mm}$. longo, fusco-tomentoso. Cymae axillares densiflorae, ambitu sphericae circ. $2.5 \mathrm{~cm}$. diametro, fusco-tomentosae, pedunculo circ. $1.5-6 \mathrm{~cm}$. longo, 1.5-2 mm. crasso suffultae, pedicello circ. $3 \mathrm{~mm}$. longo, $0.5 \mathrm{~mm}$. crasso. Corolla flava, lobis triangulari-lanceolatis, $2 \mathrm{~mm}$. longis, $1 \mathrm{~mm}$. latis, extus fusco-hirsutis intus glabris, tubo cylindrico circ. 4-5 mm. longo, $2 \mathrm{~mm}$. lato, extus dense fusco-hirsuto fauce longe adpresse villoso. Antherae anguste sagittatae, circ. $1 / 3$ e corolla emergentes $3.5 \mathrm{~mm}$. longae, $0.5 \mathrm{~mm}$. latae; filamenta circ. $2 \mathrm{~mm}$. longa, prope basin tubi inserta, in parte superiore albo-pilosa, inter se libera. Calycis lobi oblongo-lanceolati, circ. $3 \mathrm{~mm}$. longi, $0.6 \mathrm{~mm}$. lati, apice valde recurvati extus dense fusco-hirsuti, intus glabri. Ovarium glabrum, globosum, 0.5 mm. altum, squamis disci 5, glabris, oblongis, inaequilongis cinctum. Fructus pendentes cylindrici, apicem versus sensim angustati, biloculares, usque ad 8-12 cm. longi, circ. $3 \mathrm{~mm}$. crassi, fusco-tomentosi.

No. 12104! (fr.), No. 12122! (fl.), No. 12065 Kanehira-Hatusima, Dallmann, $45 \mathrm{~km}$. inward of Nabire, March 1, 1940. In edge of Agathisforests at about $500 \mathrm{~m}$. altitude.

This is well characterized by its 3 -verticillate obovate to oblanceolate laeves which are densely pubescent beneath. The species may be contrasted with Parsonsia curviscpala K. Scrum. which has much smaller glabrous leaves.

Parsonsia helicandra Hook. et Arnot. Bot. Beech. Voy. (1830) 197.

Parsonsia spiralis Wall. Cat. n. 631 (1829) nomen nudum; MarkgF. in ENGL. Bot. Jahrb. 61 (1927) 217.

No. 12880 Kanehira-Iatusima, Nabire, March 16, 1940. In strand forests.

Distrib. India to the Philippines and Formosa.

Parsonsia laevis Kanemira et Hatusima sp. nov. Fig. 7.

Suffritex scandens glaberrimus, ramis annotinis lenticellis linearibus dense notatis, circ. $3 \mathrm{~mm}$. crassis, hornotinis gracilibus, $1-1.5 \mathrm{~mm}$. crassis. 
Folia opposita, oblonga rarius ovato-oblonga, majora $13 \mathrm{~cm}$. longa, $5 \mathrm{~cm}$. lata, plerumque circ. $10 \mathrm{~cm}$. longa, $3-3.5 \mathrm{~cm}$. lata, chartacea vel tenuiter coriacea, in sicco flavo-brumnea, apice acuminata, basi auriculata vel rotundata, supra nitida, subtus nitidula, nervis lateralibus utrinque circ. 10, rectis, secundariis distinctis, costa media supra leviter impressa, subtus valde elevata; petiolo plerumque $1 \mathrm{~cm}$. longo. Inflorescentiae axillares densiflorae unilaterales glabrae, pedunculo cire. $1.5-4.5 \mathrm{~cm}$. longo, circ. $1 \mathrm{~mm}$. crasso, ramis primariis $3,1-2.5$ $\mathrm{cm}$. longis, $1 \mathrm{~mm}$. crassis, secundariis $\quad 3-5 \mathrm{~mm}$. longis. Pedicelli circ. 5 $\mathrm{mm}$. longi, $0.5 \mathrm{~mm}$. crassi, fusco-puberuli. Calyx $1.5 \mathrm{~mm}$. longus, $2.5 \mathrm{~mm}$. diametro, extus cinereopuberulus, lobis triangularibus, $0.8 \mathrm{~mm}$. longis, $1 \mathrm{~mm}$. latis. Corolla albida, membranacea,

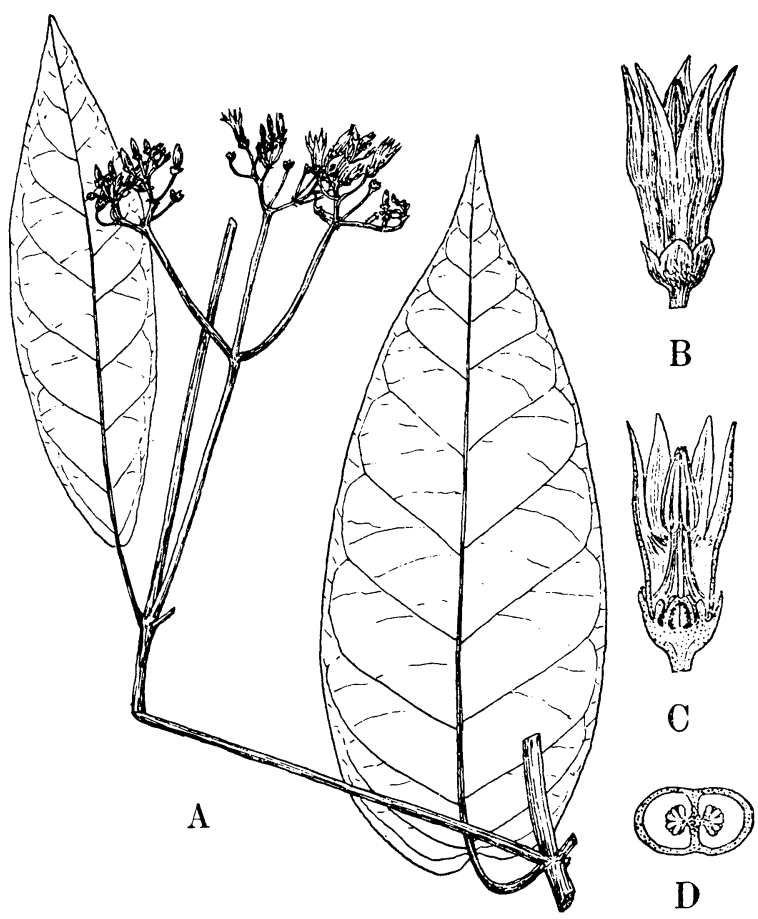

Fig. 7. Parsonsia laevis Kaneh. et Hatus. (no. 12710) $\times 2 / 3$.

A Branchlet with flowers. B Flower.

C The same in l. s. D Cross section of ovary. lobi longe ovati apice acuti, circ. $2.5 \mathrm{~mm}$. longi, $1.5 \mathrm{~mm}$ lati, extus sparse puberuli, intus glabri, tubo cylindrico circ. $3 \mathrm{~mm}$. longo, $2.5 \mathrm{~mm}$ latọ, extus sparse puberulo vel glabro, intus fauce cinereo-villoso. Antherae anguste saggittatae, $2.5 \mathrm{~mm}$ longae e corolla exsertae, filamentis circ. $3 \mathrm{~mm}$. longis. Ovarium ovoideum, glabrum, $1 \mathrm{~mm}$. altum, squamis oblongis, glabris, circ. duplo superantum.

No. 12710 Kanemra-Hatusima, Boemi, $40 \mathrm{~km}$. inward of Nabire, March 10, 1940. In edge of Agathis-forests at about $400 \mathrm{~m}$. altitude.

This is well characterized by its oblong glabrous leaves with auriculate bases and by its glabrous inflorescences. This bears some resemblance to Parsonsia mominensis KaneH. et Hatus., from which it differs by its much thicker and larger oblong leaves shining on both surfaces, shorter peduncles, and different floral structure. 
Parsonsia momiensis Kanehira et Hatusima sp. nov. Fig. 8.

Frutex scandens, glaberrimus, ramulis gracilibus, circ. $1.5 \mathrm{~mm}$. crassis. Folia opposita, glabra, chartacea, petiolo circ. $1 \mathrm{~cm}$. longo, $1 \mathrm{~mm}$. crasso.

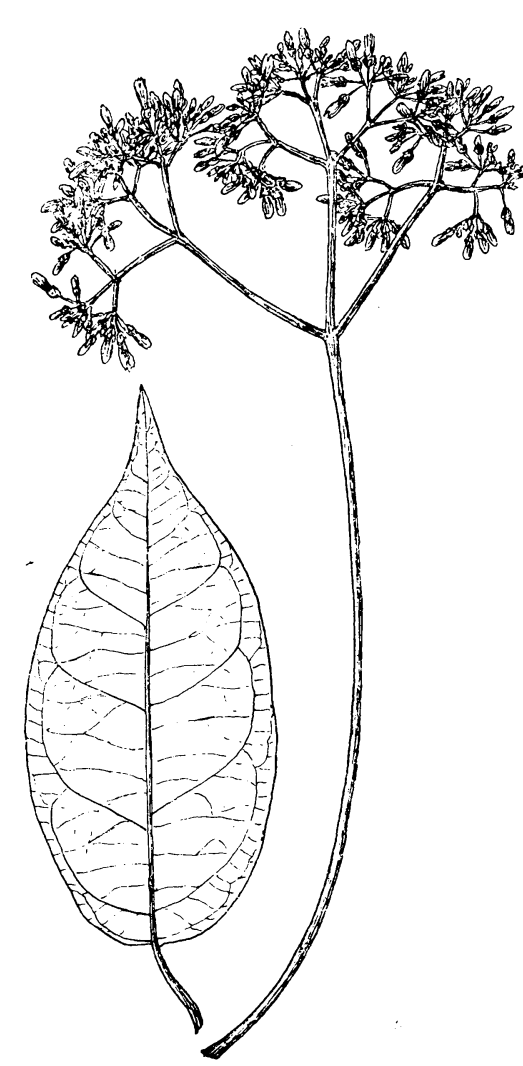

Fig. 8. Parsonsia momiensis KaneH. et Hatus. (no. 13409) $\times 2 / 3$. Lamina elliptica vel ovato-elliptica, $6.6-9 \mathrm{~cm}$. longa, $2.8-3.8 \mathrm{~cm}$. lata, apice acuminata, basi rotundata, margine vix revoluta, supra nitidula, subtus opaca, costa media supra plana, subtus haud elevata, nervis lateralibus utrinsecus 7 vel 8 , rectis prope marginem conjunctis, utrinque vix elevatis, secundariis tertiariisque utrinque distinctis sed vix elevatis. Inflorescentiae axillares, glabrae, eymosae, multiflorae, circ. $8 \mathrm{~cm}$. latae, $5 \mathrm{~cm}$. longae, pedunculo $17 \mathrm{~cm}$. longo, $1.5 \mathrm{~mm}$. crasso suffultae, trichotome ramosae, ramis primariis circ. $4 \mathrm{~cm}$. longis, $1 \mathrm{~mm}$. crassis, secundariis cire. $1 \mathrm{~cm}$. longis, $1 \mathrm{~mm}$. crassis, tertiariis $3-4$ $\mathrm{mm}$. longis, $0.8 \mathrm{~mm}$. erassis. Pedicelli 3-3.5 mm. longi, $0.5 \mathrm{~mm}$. crassi sparse fusco-pilosuli. Calycis lobi extus sparse fusco-pilosi, late triangulares, $0.5 \mathrm{~mm}$. longi, $0.5 \mathrm{~mm}$. lati, apice acuti. Corolla pallide viridia, circ. $5 \mathrm{~mm}$. longa, extus glabra, lobis ovato-lanceolatis, apice acutis, $3 \mathrm{~mm}$. longis, $1 \mathrm{~mm}$. latis, paullo longioribus quam tubo, tubo $2 \mathrm{~mm}$. longo, $1.8 \mathrm{~mm}$. crasso, intus in fauce villoso. Filamenta $2 \mathrm{~mm}$. longa, prope basin tubi inserta. Antherae anguste lanceolatae, $3 \mathrm{~mm}$. longae, $0.5 \mathrm{~mm}$. latae. Ovarium glabrum, late ovoideum, circ. $8 \mathrm{~mm}$. altum, paullo longis quam squamae disci.

No. 13409 Kanehira-Hatusima, Momi, April 3, 1940. In edge of primary rain-forests; along the trail to the Lake Angi at about $300 \mathrm{~m}$. altitude.

Parsonsia rubra Kanehira et Hatusima sp. nov. Fig. 9.

Frutex alte scandens, ramulis circ. $4 \mathrm{~mm}$. crassis, primo adpresse ferrugineo-pilosis, mox glabrescentibus. Folia opposita, tenuiter coriacea, elliptico-oblonga vel oblonga vel obovato-oblonga, apice breviter acuminata, 
basi rotundato-cuneata vel cuneata, utrinque opaca, in sicco cinereo-fuscescentia, supra glabra, subtus adpresse ferrugineo-pilosa mox glabrescentia, 8-13 cm. longa, plerumque $4 \mathrm{~cm}$. lata, nervis lateralibus utrinsecus 7-9,

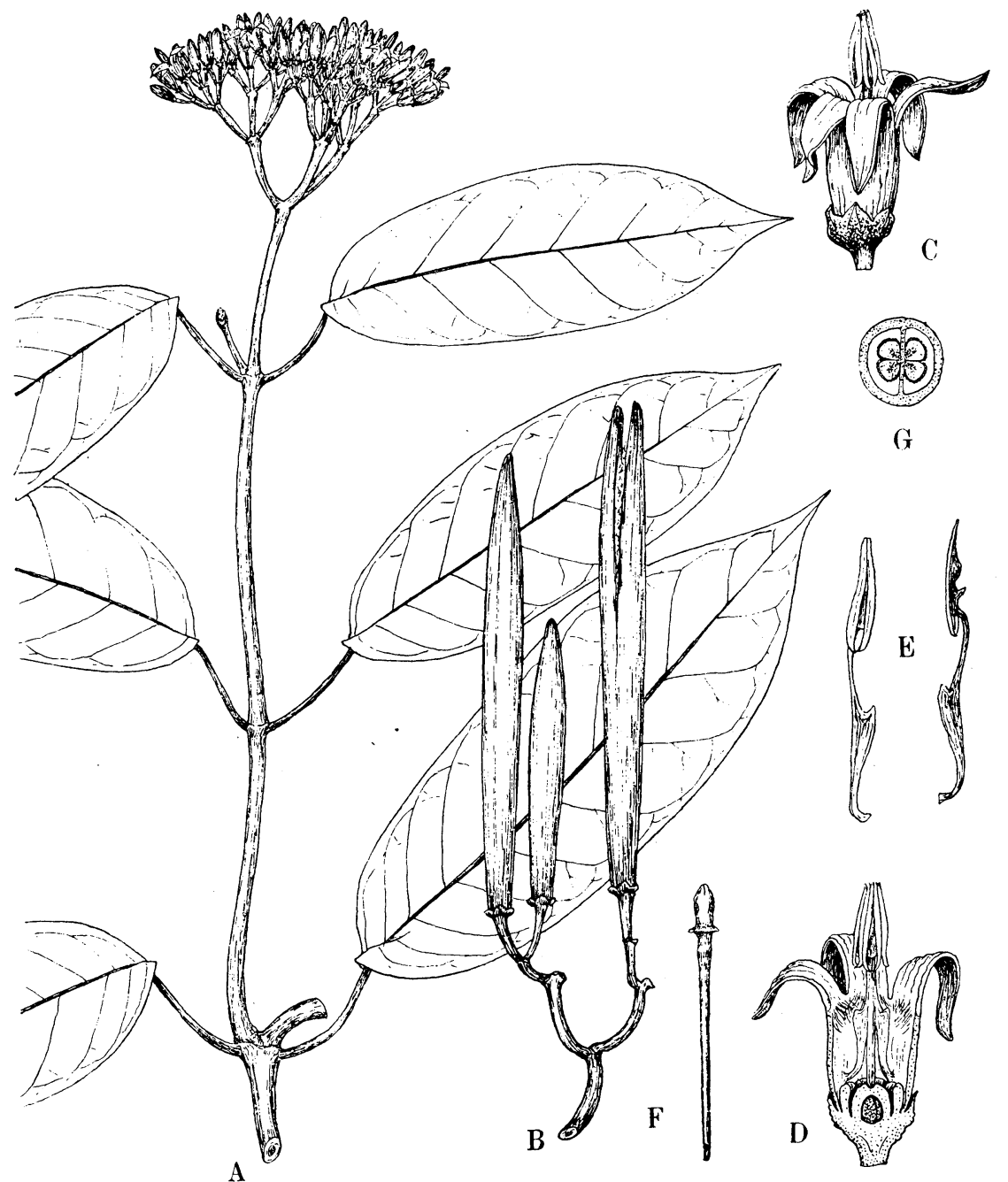

Fig. 9. Parsonsia rubra Kaneh. et Hatus.

(no. 12220) $\times 2 / 3$.

A Branchlet with flowers. B Fruits. C Flower. D The same in 1. s.

E Stamens. F Style. G Cross section of ovary.

rectis prope marginem conjunctis, supra impressis, subtus valde elevatis, venis reticulatis subtus distinctis, supra obsoletis; petiolo plerumque 2-2.5 cm. longo. Inflorescentiae axillares, cymosae, densiflorae, circ. $6 \mathrm{~cm}$. longae, pedunculo $6-7 \mathrm{~cm}$. longo, $2.5 \mathrm{~mm}$. crasso suffultae, adpresse ferrugineo- 
pilosae, ramis primariis $3,2 \mathrm{~cm}$. longis, $1.5-2 \mathrm{~cm}$. crassi, secundariis $0.5-1$ cm. longis, $1.5 \mathrm{~mm}$. crassis, tertiariis (pedicellis) 5-6 mm. longis, $0.8 \mathrm{~mm}$. crassis. Calycis lobi extus ferrugineo-puberuli, $1 \mathrm{~mm}$. alti et lati, late triangulares, apice acuti. Corolla rubra, 7-8 $\mathrm{mm}$. longa, extus sparsissime puberula, intus glabra, lobis lanceolatis, $5 \mathrm{~mm}$. longis, $1 \mathrm{~mm}$. latis, tubo $3 \mathrm{~mm}$. longo, 1.7-2 mm. crasso, intus in fauce albo-villoso. Filamenta $4 \mathrm{~mm}$. longa, prope basin tubi inserta, in parte superiore albo-pilosa, inter se et cum stylo cohaerentia. Antherae longe ovatae, $4 \mathrm{~mm}$. longae, $0.8 \mathrm{~mm}$. latae, glabrae, apicibus breviter appendiculatis. Stigma clavatum, in basi annulatum. Ovarium glabrum, globosum, $1 \mathrm{~mm}$. altum, squamis disci 5, glabris, oblongis. Fructus in pedicellis incrassatis e calycibus disciformiter dilatatis, pendentes, cylindracei, apicem versus sensim angustati, biloculares, usque ad $10 \mathrm{~cm}$. longi, $8 \mathrm{~mm}$. lati. Semina multa, fusiformia, $4 \mathrm{~mm}$. longa, $1 \mathrm{~mm}$. lata, apice coma sordida, $5 \mathrm{~mm}$. longa coronata.

No. 12220 Kanehira-Hatusima, Dallmann, $45 \mathrm{~km}$. inward of Nabire, March 2, 1940. In Agathis-forests at about $500 \mathrm{~m}$. altitude.

This is well characterized by its dull leaves which are densely reticulated beneath and by its long-stalked inflorescences bearing large red flowers.

Parsonsia vaccinioides MARkgF. in ENGL. Bot. Jahrb. 61 (1927) 216.

Lyonsia albiflora GibB, Dutch N. W. Guinea (1917) 177.

Lyonsia vaccinioides MarkgF. in Nova Guinea 14 (1926) 290.

Nos. 13460, 13656 Kanehira-Hatusima, Angi, Arfak Mts., April,6, 1940. In spinneys on the summit of Mt. Koebre. Scandent, flowers pale yellow.

Distrib. Endemic.

Parsonsia warenensis Kanehira et Hatusima sp. nov. Fig. 10.

Suffrutex scandens, ramulis fusco-villoso-puberulis, circ. $2 \mathrm{~mm}$. crassis. Folia opposita, ovato-elliptica, rarius ovato-oblonga, apice mucronata vel acuta vel brevissime acuminata, basi cordata vel truncato-cordata, margine vix revoluta, $3.5-8 \mathrm{~cm}$. longa, $3-5 \mathrm{~cm}$. lata, utrinque sparce setoso-puberula, scabra vel nitidula, in sicco brunnea, nervis lateralibus plerumque 5, \pm arcuatim adscendentibus, supra impressis, subtus elevatis, venis reticulatis utraque facie distinctis, supra leviter subtus vix impressis. Inflorescentiae axillares, unilaterales, cymosae, laxiflorae, ambitu globosae, circ. $3.5 \mathrm{~cm}$. diametro, fusco-villosae, pedunculo $1-1.5 \mathrm{~cm}$ longo. Pedicelli plerumque $5 \mathrm{~mm}$. longi, $0.5 \mathrm{~mm}$. crassi. Corolla flava, lobis anguste triangularibus, $1.5 \mathrm{~mm}$. longis, $1 \mathrm{~mm}$. latis, intus glabris, tubo cylindrico, $5 \mathrm{~mm}$. longo, $2 \mathrm{~mm}$. lato, extus fauce villoso-strigoso, intus supra medium fusco-villoso. Antherae anguste sagittatae, $3 \mathrm{~mm}$. longae, $0.8 \mathrm{~mm}$. latae, circ. 1/5 e corolla 
exsertae; filamenta $3.5 \mathrm{~mm}$. longa, in parte superiore pauce pilosa. Calyces cyathiformes, $3 \mathrm{~mm}$. alti, $3 \mathrm{~mm}$. diametro, extus adpresse fusco-strigosovillosi, lobis usque ad basin liberis, anguste triangularibus, $1 \mathrm{~mm}$. latis, 2-2.5 mm. longis. Ovarium glabrum, globosum, $0.5 \mathrm{~mm}$. altum; squamis

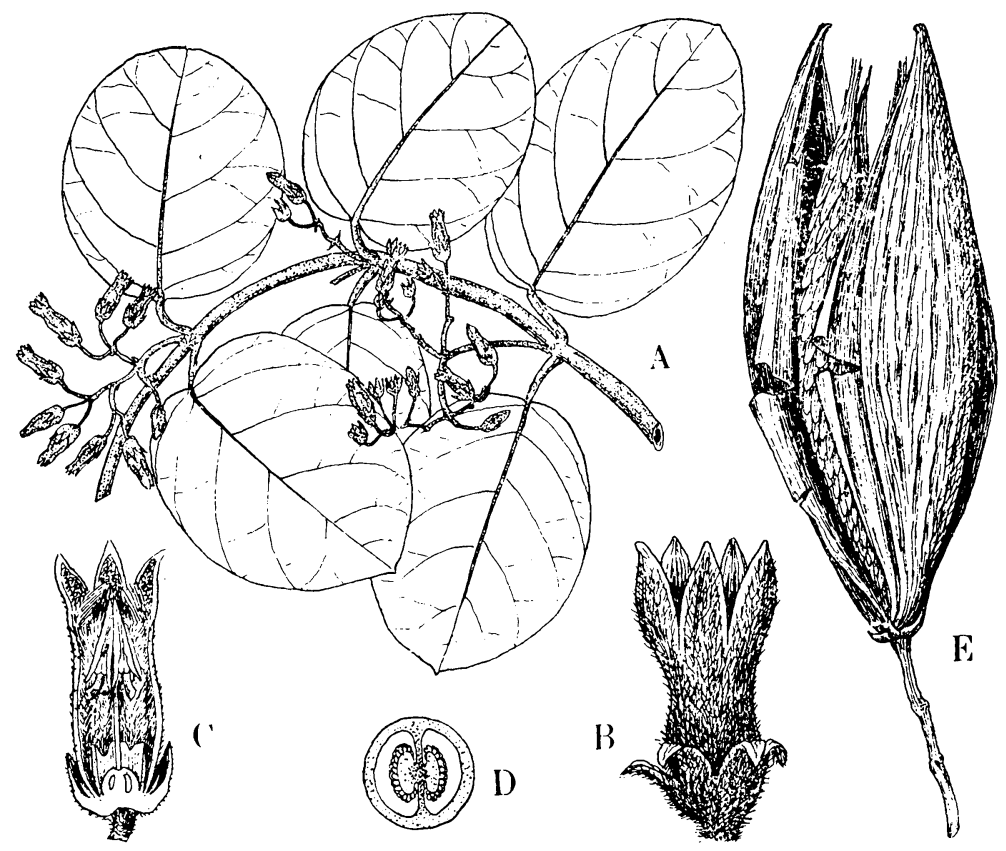

Fig. 10. Parsonsia warenensis KANEH. et Hatus. (no. 13125) $\times 2 / 3$.

A Branchlet with flowers. B Flower. C The same in 1. s.

D Cross section of ovary. E Fruit.

disco 5, glabris oblongis, circ. $1 \mathrm{~mm}$. longis. Fructus fusiformes, $9 \mathrm{~cm}$. longi, $2 \mathrm{~cm}$. lati ; semina multa, fusiformia, $1 \mathrm{~mm}$. longa, $1.5 \mathrm{~mm}$. lata, coma sericea, circ. $2 \mathrm{~cm}$. longa, pallide brumnea coronata.

No. 13125 Kanehira-Hatusima, Waren, Momi, March 28, 1940. Scandent, in rain-forests, limestone mountain at about $600 \mathrm{~m}$. altitude.

This is most closely related to Parsonsia cyathocalyx MARKgF.

Rejoua aurantiaca Gaudich. Bot. Freyc. Voy. (1826) 451, t. 61 ; Markaf. in Not. Bot. Gart. Berlin-Dahlem 12 (1935) 546.

Tabernaemontana aurantiaca GAUdicH. l. c. 50 ; MarkgF. in Nova Guinea 14 (1926) 286 ; ENGL. Bot. Jahrb. 61 (1927) 201; Kanehira, Enum. Mic. Pl. (1935) 396.

No. 11420 Kanehira-Hatusima, Nabire, Feb. 23, 1940. Fairly common 
in dilluvial rain-forests at low altitudes. A tree $5 \mathrm{~m}$. high with pendant orange-red fruits.

Distrib. New Guinea and its neighbouring islands.

Rauwolfia rostrata Markgr. in Engl. Bot. Jahrb. 61 (1927) 188.

Nos. 11572, 11544, 12895 Kanehira-Hatusima, Nabire, Feb. 25, 1940 ; in rain-forests at low altitudes; a shrub, $1.5 \mathrm{~m}$. high flowers yellowish white. No. 11768 Kanehira-Hatusima, Boemi, $40 \mathrm{~km}$. inward of Nabire, March 11, 1940 ; in Agathis-forests at about $400 \mathrm{~m}$. altitude; a shrub 1'm. high, fruits red.

We have not seen the type of the species, but our specimens cited above agree with the original description, except that the leaves are somewhat thinner and quite glabrous on both surfaces.

Distrib. Endemic, the type was from Manokwari.

Voacanga papauna (F. v. Muell.) K. Schum. in Engler-Prantl, Nat. Pflanzenf. 4, 2 (1895) 149; K. Schum. et Lautb. Fl. Deutsch. Schutzg. Sïdsee (1901) 503; MarkgF. in Engl. Bot. Jahrb. 61 (1927) 204.

Orchipeda papuana F. v. Muelu. Desc. Notes on Pap. Pl. 2 (1886) 30.

No. 11844 Kanehira-Hatusima, Tjaban, about $30 \mathrm{~km}$. inward of Nabire, Feb. 28, 1940. In edge of rain-forests at about $100 \mathrm{~m}$. altitude. A tree $5 \mathrm{~m}$. high, flowers white.

Distrib. Eastern New Guinea.

Clarence E. Kobuski: Studies in the Theaceae, IX.

Beceived September 27, 1941.

In the present paper are enumerated the species of Theaceae collected by Professor R. Kanehira and S. Hatusima in Dutch New Guinea during the year 1940. All the material used and cited in this study, with the exception of two numbers collected by L. J. Brass of the Archbold Expedition to New Guinea, were of this collection.

The author is extremely grateful to the collectors for the opportunity to study this material. ${ }^{*}$

\section{Gordonia EluIs.}

Gordonia papuana Koвuskr in Jour. Arnold Arb. 21 : 136. 1940. Fig. 1. Dutch New Guinea: Waren, 60 miles south of Manokwari, in rain

* Figures in this paper were drawn by T. MASUmi and photos were taken by M. Sigematu (R. K.) 
forest on limestone mountain, alt. $400 \mathrm{~m} .$, R. KaneHira \& S. Hatusima 13094 , March 26, 1940 (tree $10 \mathrm{~m}$. high with white flowers).

No flowering material is available for dissection but the leaves, dull on both surfaces, present sufficient evidence to separate this species from $G$. Brassii Kobuski.

\section{Ternstroemia Mutis.}

\section{Ternstroemia Kanehirai}

Kobuski, 11. sp. Fig. 2.

Frutex erectus, 3-4 m. altus, ramis griseis, ramulis verticillatis rubro-brumneis glabris. Folia obovata, verticillata, apice ramulorum congesta, 3-4 (-5.5) cm. longa et 1-2(-3.5) cm. lata, glabra, coriacea, apice obtusa vel

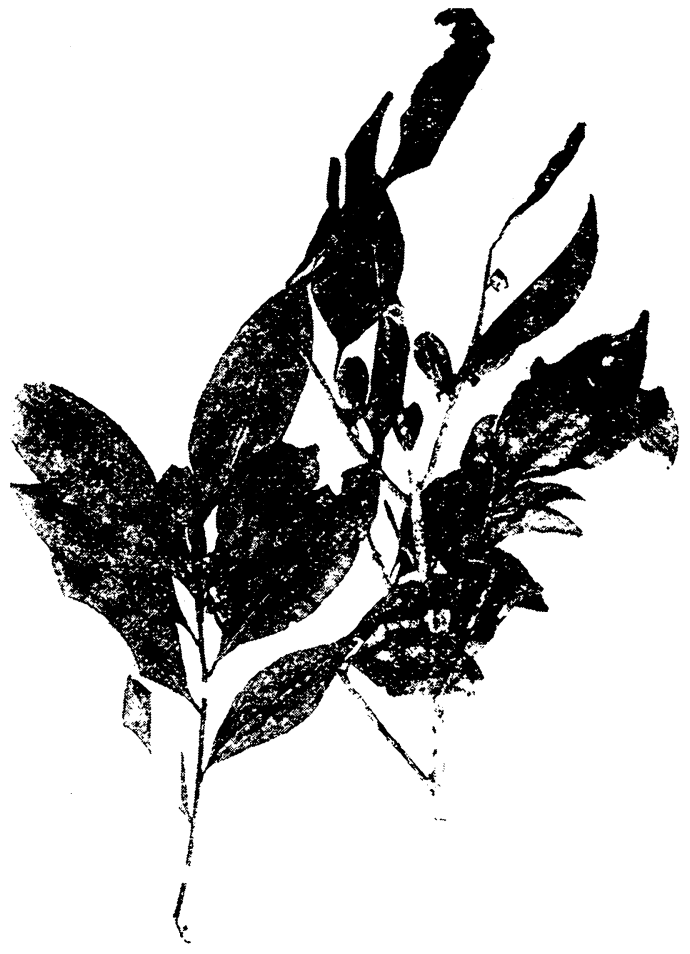

Fig. 1. Gordonia papuana Kobuski. (no. 13094) $\times 1 / 4$.

rotundata, basi attenuata, maroine integerrima, revoluta, venis obscuris. petiolis $0.5-1.0 \mathrm{~cm}$. Iongis glabris. Flores dioeci, 1-2 in axillis foliorum, pedicellis glabris 4-6 mm. longis, bracteolis 2 oppositis vel suboppositis 2-3 mm. longis et ca. $2 \mathrm{~mm}$. latis ovatis vel deltoideis glabris crasso-ligneis, apiculatis, margine pauce glandulo-ciliolatis; flores ô (KANEHIRA \& HATUsima 14023): sepala 5, imbricata, inaequalia, concava, glabra, pergamentacea, subrotundata, $4-5 \mathrm{~mm}$. longa et $3.5-4.5 \mathrm{~mm}$. lata; petala 5 , arctissime imbricata, vix per anthesim soluta, flore dissecto ealyptratim decidua, exterioribus ca. $6 \mathrm{~mm}$. longis et $5 \mathrm{~mm}$. latis, interioribus ca. $6 \mathrm{~mm}$. longis et $2 \mathrm{~mm}$. latis; stamina \pm 50 in serie unico, filamentis $1.5-2.0 \mathrm{~mm}$. longis basi connatis, antheris $1.5-2.0 \mathrm{~mm}$. longis, linearibus, apice basique ovatis, obovatis vel apiculatis; flores o (Kanefira \& Hatusima 13529) : sepala $\overline{5}$, imbricata, inaequalia, glabra, concava, subrotundata, pergamentacea, 4-5 $\mathrm{mm}$. longa et $3.5-4.5 \mathrm{~mm}$. lata, exterioribus margine leviter glandulo-ciliolatis, interioribus margine seariosis ; petala 5, imbricata, inaequalia, 5-6 mm. longa, exterioribus ca. $4 \mathrm{~mm}$. latis et interioribus margine scariosis, ca. 2.5 $\mathrm{mm}$. latis; ovarium conicum, glabrum, $4 \mathrm{~mm}$. longum, basi ca. $3 \mathrm{~mm}$. diam. 
in stylum $1 \mathrm{~m}$. longum attenuatum, 2- vel 3-loculare, ovulis ca. 16 . Fructus (Kanehira \& Hatusima 14000) conicus, glaber, ruber, ca. $1.5 \mathrm{~cm}$. longus et $1.5 \mathrm{~cm}$. basi diam., seminibus $8-12$ roseis ca. $7 \mathrm{~mm}$. longis et $4 \mathrm{~mm}$. latis.

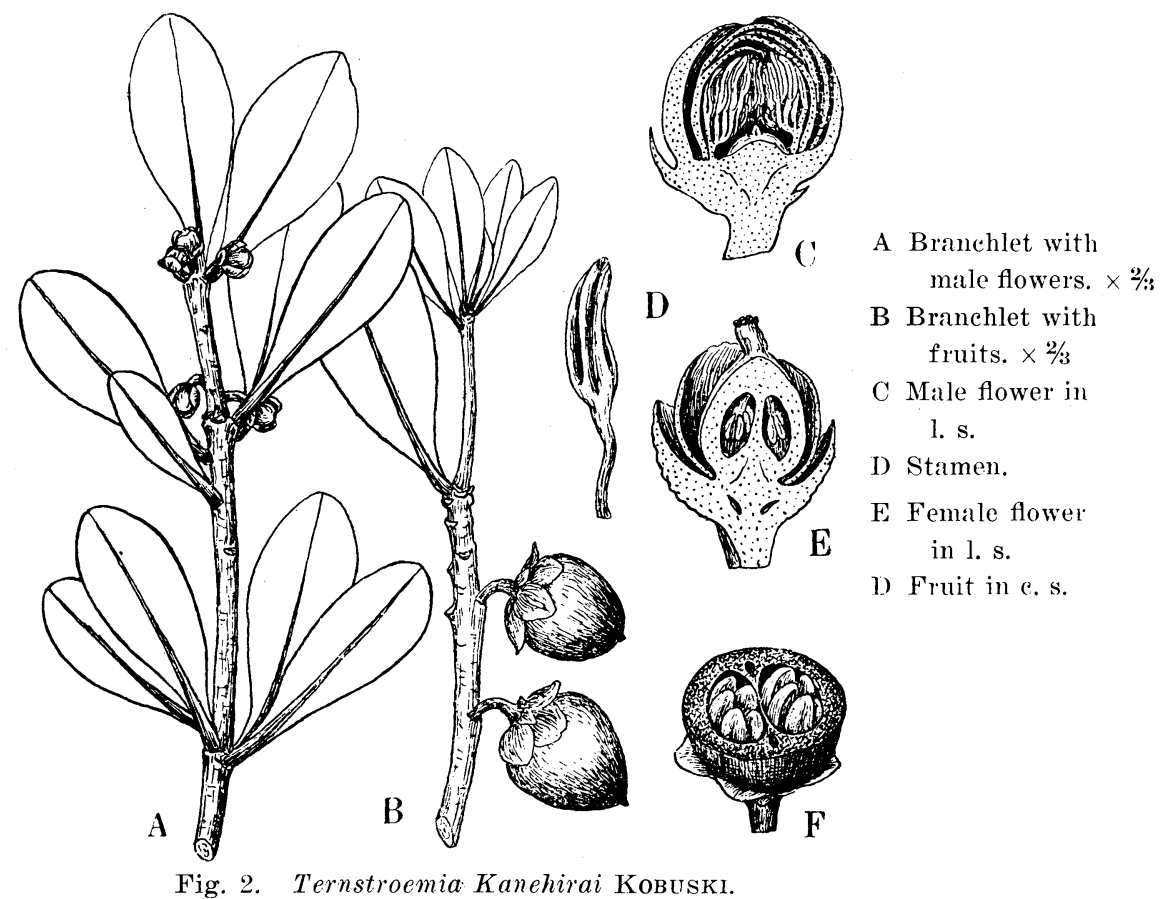

Dutch New Guinea: Angi, Arfak Mts., in forest on the eastern ridge rumning up to Lake Gita, alt. 2000 m., R. Kanehira \& S. Hatusima 13529 (type, AA), April 5, 1940 (shrub 4 m.).-Angi, Arfak Mts., in low spinney's on the open summit of Mt. Koebre, alt. 2200-2300 m., R. Kanehira \& S. Hatusima 13720, 14000, 14023, April 6-9, 1940 (shrub 3 m.).

This new species presents the following outstanding characteristies:

1. The verticillate arrangement of both branchlets and leaves.

2. The ovary in the pistillate flower approximately eight ovules in each cell and the fruit shows four seeds in each locule.

These cháracters separate T. Kanehirai from all other species known in New Guinea.

3. The unusually small flowers.

4. The petals of the staminate flowers are so closely imbricated at anthesis that it is necessary to tease them out very carefully in dissection. After boiling the flowers for dissection, it was noted that the closed corolla (with stamens within) always dropped off, 
simulating a calyptre; however, no evidence of an ovary could be detected. Strangely enough, no staminate flowers in any stage were seen with spreading or even open petals, though in many instances the sepals were found spreading or lying open.

It is a pleasure to name this species in honor of Professor R. KanEHIRA, the senior member of the collecting trip to Dutch New Guinea, of which these specimens are a small part.

Ternstroemia sphondylophora Koвuski in Jour. Arnold. Arb. 21: 150. 1940. Fig. 3.

Dutch New Guinea: Angi, Arfak Mts., in low spinneys on burned open summit of Mt. Koebre, ait. 2300 m., R. Kanemira \& S. Hatusima

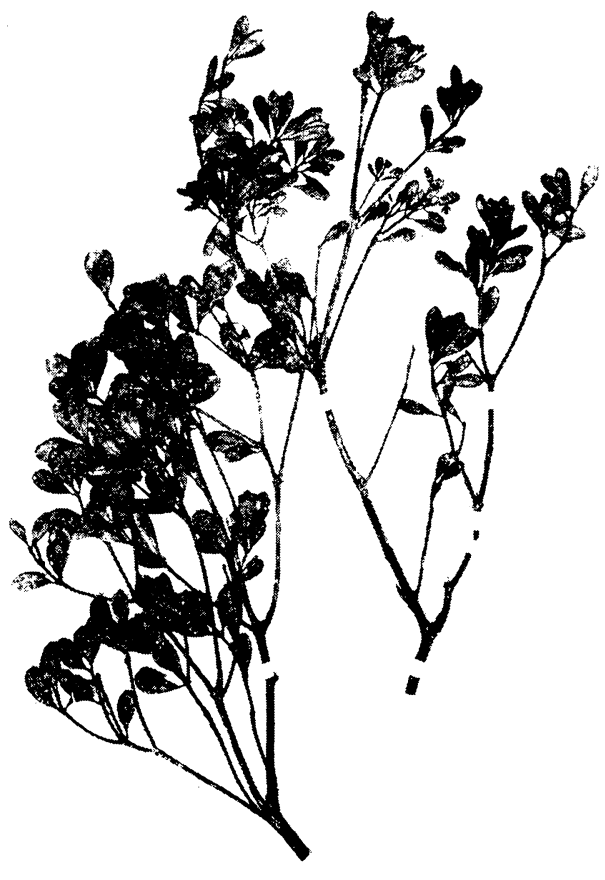

Fig. 3. Ternstroemia sphondylophora KobUsKi. $\times 1 / 4 \quad($ no. 14025$)$ 14025, April 9, 1940 (shrub 2 m.). The verticillate angled branchlets and the small verticillate, spathulate leaves are the distinguishing characters of this species. In the specimen cited above, the leaves are generally narrower $(0.5$ cm. wide) than the specimens cited under the original description $(0.5-1.2 \mathrm{~cm}$. wide).

\section{Eurya Thuniberg.}

Eurya Kanehirai Koвuski, n. sp.

Frutex vel arbor parva, $4 \mathrm{~m}$. alta, ramulis teretibus brumneis, hornotinis pubescentibus. Folia membranacea, lanceolata vel oblongo-ovata, $7-10 \mathrm{~cm}$. longa et 2-3 cm. lata, supra glabra, subtus (costa) sparse pubescentia, apice acuminata basi cuncata in petiolum parvum (2-3 mm. longum) pubescentem attenuata. Flores dioeci, 1-2 in axillis foliorum, pedicellis $1.0-1.5 \mathrm{~mm}$. longis sparse hirsutis, bracteolis 2 hirsutis inaequalibus minutissimis $1 \mathrm{~mm}$. vel minus longis apiculatis; flores ô (Kanehira \& Hatusima 14231): sepala 5, imbricata, inaequalia, hirsuta, deltoideo-obtusa, parva, ca. $1 \mathrm{~mm}$. longa et $1.5-1.7 \mathrm{~mm}$. lata, vix concava, margine non glandulosa; petala 5 , imbricata, parva, oblonga, inaequalia, ca. $2.5 \mathrm{~mm}$. Jonga et $1.0 \mathrm{~mm}$. lata, basi connata; stamina 
5 , cum petalis alternata, filamentis antherisque ca. $1 \mathrm{~mm}$. longis ; pistillodio glabro linearo ca. $1 \mathrm{~mm}$. longo; flores $q$ (Kanehira \& Hatusima 12929): sepala 5, parva, imbricata, inaequalia, hirsuta; obtusa ea. $1 \mathrm{~mm}$. longa et

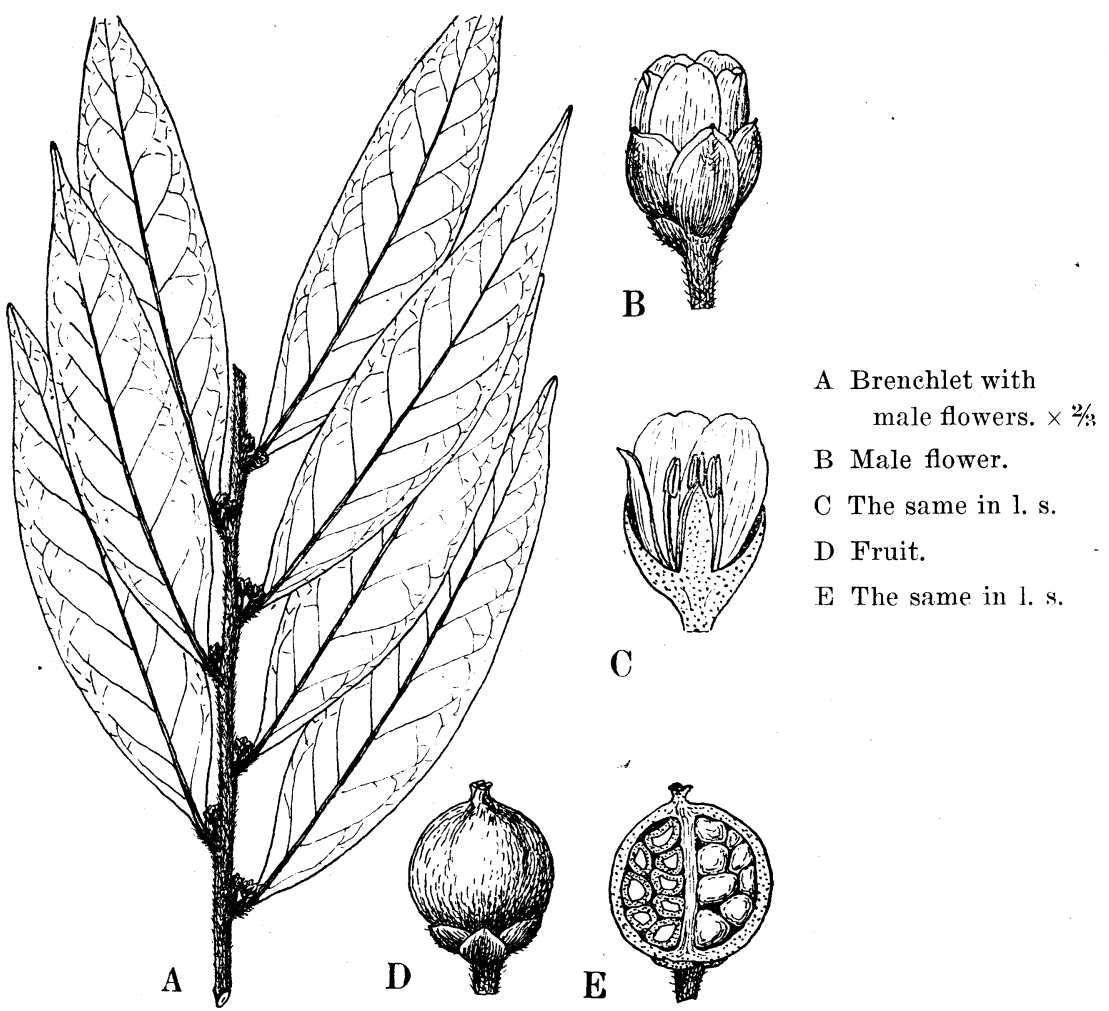

Fig. 4. Eurya Kanehirai KoвUsKI.

$1.5 \mathrm{~mm}$. lata; petala 5, imbricata, inaequalia, ca. $3 \mathrm{~mm}$. longa; ovarium globosum, glabrum, ca. $1 \mathrm{~mm}$. vel vel minus longum, 4-loculare, multiovulatum; stylum parvissimum, minus quam $0.5 \mathrm{~mm}$. longum, apice 4-partitum, stigmatibus recurvatis. Fructus parvus, globosus $3 \mathrm{~mm}$. diam., 4-locularis.

Dutch New Guinea: Waren, sixty miles south of Manokwari, in forest on dry hill, alt. 300 m., R. Kanehira \& S. Hatusima 12929 ( q type), March 21, 1940 (4 m. high).-Waren, sixty miles south of Manokwari, in open forest on dry hill, alt. 200 m., R. Kanehira \& S. Hatusima 14231 ( $\hat{\text { ) }}$, April 19, 1940 (4 m. high).

The acuminate, membranaceous leaves, the five stamens in the staminate flowers, the four-celled ovary and four-parted style and the very short sepals and petals all help to distinguish $E$. Kanehirai from the other Papuasian species. 
Cited here dubiously might be Kanehira \& Hatusima 13028 and 13134. Both numbers, according to the collectors, were collected at Waren, the same locality as the two specimens 12929 and 14231 cited under the species. However, 13028 and 13134 were collected at sea-level and belong to the strand forests, while 12929 and 14231 were collected on dry hill-sides at 300 and $200 \mathrm{~m}$. altitude. Number 13028 has staminate flowers which agree with 14231 in size of pedicels, bracteoles, sepals, petals and stamens (5). The leaves are shorter and less acuminate. Number 13141 has pistillate flowers which agree with the type, no. 12929 in flowering parts, including the four-parted style and fourcelled ovary and fruit. Here, the leaves vary more than those of 13028 in that they are smaller, obovate and more serrulate.

This species is named for Professor R. Kaneirira of the Kyusyu Imperial University, the senior collector of the above-mentioned herbarium material.

Eurya Groffii Merrill in Philipp. Jour. Sci. 25: 247.

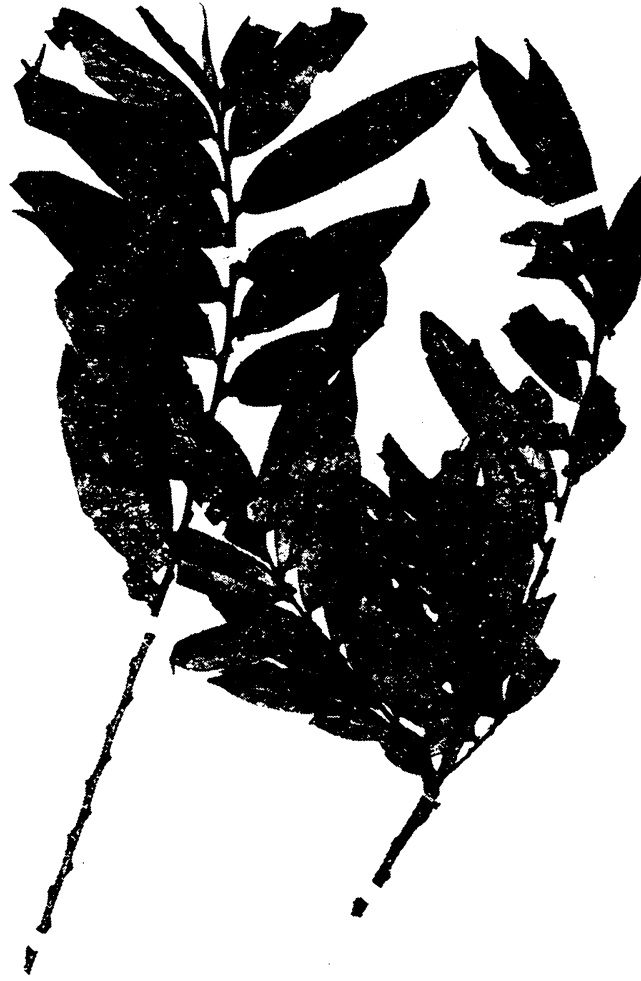

Fig. 5. Eurya Groffii MerR. $\times 1 / 4$. (no. 13764) 1919.-Koвuski in Jour. Arnold Arb. 21 : 155. 1940. Fig. 5.

Dutch New Guinen: Angi, Arfak Mts., in forest near Iray, Lake Giji, alt. 1900 m.. R. Kanehira \& S. Hatusima 13764, April 7, 1940 (8 m. high).

Eurya tigang Schumann \& Lauterbach, Fl. Deutsch. Schutzgeb. Südsee, 44. 1901.-Diels in Bot. Jahrb. 57 : 434. 1922.-Koвuski in Ann. Missouri Bot. Gard. 25 : 347. 1937; Jour. Arnold Arb. 21 : 161. 1940.

Dutch New Guinea: Angi, Arfak Mts., in forest on the eastern ridge running up to Lake Gita, alt. 1800 m., R. Kanehira \& S. Hatusima 13462, April 5, 1940 (tree 10 m.). 
Eurya longisepala Koвuski, n. sp.

Arbor gracilis, 4-5 m. alta, ramulis teretibus brumneis hornotinis sericeis. Folia coriacea, lanceolata, 9-13 $\mathrm{cm}$. longa et 2-3 cm. lata, apice acuminata, basi cuneata et abrupte in minutum petiolum attenuata, lamina supra glabra, lucida, subtus indumento ad apicem laminae verso, laxe adpresso vel accumbente sericen-pubescente, costa indumento sub angulo $45^{\circ}$ patente more proprio hirsuta, margine serrulata, revoluta. Flores dioeci, 1-4 in axillis foliorum, pedicellis $2-3 \mathrm{~mm}$. longis dense hirsutis, bracteolis 2 deltoideis dense hirsutis $2-4 \mathrm{~mm}$. longis et $2-3 \mathrm{~mm}$. latis; flores o (BRAss $^{2}$ 11454) : sepala 5, imbricata, ovata, concava, inaequalia, exterioribus 2 dense pubescentibus ca. $5 \mathrm{~mm}$. longis et $2.5-3.0 \mathrm{~mm}$. latis, pergamentaceis, margine glandulosis, interioribus 3 glabris $4.5-5.0 \mathrm{~mm}$. longis et $2.5-3.0 \mathrm{~mm}$. latis, margine scariosis (non glandulosis) membranaceis; petala 5 , imbricata, alba, 5-6 $\mathrm{mm}$. longa et $3-4 \mathrm{~mm}$. lata, basi connata; stamina 5 , cum petalis alternata, ca. $5 \mathrm{~mm}$. longa, filamentis ca. $3 \mathrm{~mm}$. longis $+1 \mathrm{~mm}$. crassis, antheris late sagitattis ca. $2 \mathrm{~mm}$. longis; pistillodio oblongo, ca. $5 \mathrm{~mm}$. longo, apice acuminato; flores $q$ (BRASS 115601) : sepala 5, imbricata, ovata, concava, inaequalia, exterioribus 2 dense pubescentibus $5.5-6.0 \mathrm{~mm}$. longis et ca. $3 \mathrm{~mm}$. latis apice apiculatis, maroine glandulosis, interioribus 3 , glabra vel subglabris ca. $4.5 \mathrm{~mm}$. longis et $2.5 \mathrm{~mm}$ latis, margine seariosis (non glandulosis) ; petala 7, imbricata, oblonga, 5--6 mm. longa et 2.0-2.5 mm. lata, recurvata, apice rotunclata, ad medio comnata ovarium non visum. Fructus glaber, globosus, ca. $7 \mathrm{~mm}$. diam., 5-locularis, multi-seminatus; stylo minutissimo ( $1 \mathrm{~mm}$. vel minus longo) apice j-partito; stigmatibus 5 recurvatis.

Dutch New Guinea: Bele River, eighteen kilometers northeast of Lake Habbema, frequent in second growth forest, alt. $2350 \mathrm{~m}$., L. J. Brass 11560A ( 9 , AA, type), Nov. 1938 (slender tree, 4-5 m. high).-Bale River, eighteen kilometers northeast of Lake Habbema; common in low second growths, alt. 2350 m., L. J. BRass 11454 o, Nov. 1938 (flowers white).

The long ovate sepals, the seven petals of the pistillate flower joined for approximately one-half their entire length, the five sagittate stamens and thickened filaments of the staminate flower, plus the unusual pubescence of the leaves (loosely appressed or accumbent on the leaf-blade, directed toward the apex; spreading at an angle of forty-five degrees on the midrib) are the outstanding characters of this new species.

In an earlier paper, these two Brass numbers, 11560.1 and 11454.4 were cited dubiously under Eurya tigang Lauterb. However, subsequent study of new material shows that a new and very distinctive species is represented. 


\section{ニニーギニアノ植物研 究 $(\mathrm{V})$ (和文摘要)}

$\begin{array}{llll}\text { 金 } & \text { 本 } & \text { 僦 } \\ \text { 初 } & \text { 鼠 } & \text { 任 彦 }\end{array}$

\section{夾 竹 桃 科}

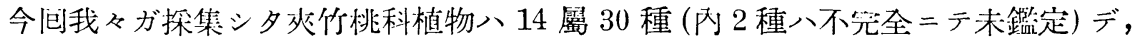
從來ニューギニアョリ知ラレタ 28 屬 80 種 (栽培品习除ク) =比シ略归數二過ギナ イガ 9 種郎チ探集品ノ約 3 割强ノ新種ガアリ，ニユーギニアノ植物調查ガ如侧二不 充分デアルカガ判ル (之ノ事實八他)科デハ更二著シク，8～9 割)新種ヨ有スル科 サヘモアル)。

ニューギニア産ノ夾竹桃科八低地林二最モ種類ガ多ク, 中高地, 高地二行クニツ レ特種, 屬习除ク外減少シテキル。屬トシテ種類二渻ムノ八Alyxia 及 Parsonsia 2 屬デ, 殊二前者八高地帶二於イラ・著シク分化發達シ, ソノ種類二富ミ, 且ソノ種子 八後者ノ如ク風ニヨツテ遠ク散布サレルコトガナイノデ末踏查ノ多クノ孤立峯二八 未記録ノ固有種ガ们多數アルモノト考へラレル。從ツテ将來ニューギニアノ必竹桃 科ノ種類八主トシテ本网屬ニヨツテ增加スルモノト想像サレル。

生活型トシテハ落性ノモノガ斷然多ク，大巂木トナリ森林ノ上厤樹冠ノ形成二與 ルモノ八只Alstonia 屬ダケデアル。中否木トシテハ低地林殊二海岸二近イ测積穈上

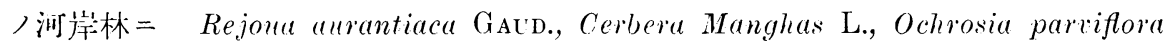
HENSt., Lepiniopsis ternatensis VAL. 等ガ見ラレ, 內前三者ノ果賽八海流ニヨツテ

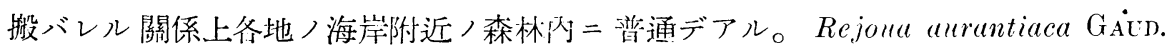

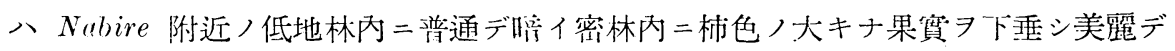
アル。又 Nabire 秋ノ河岸休ノ林緣ニ八みふくらぎ二似夕白イ大キナ花ヨ着ヶル小

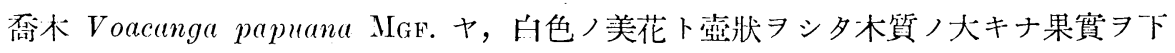
垂スル Melodinus ヤ，美シイ紅イ花习着ケルさかきかづら近緣ノPapuechites 等ノ 藤本ガ兒ラレ，密林內二大レバ高サ 1 米內外デ小サナ赤イ實 Rauwolfia rostratu IIGF. ガ稀デナイ。潮風ノ衙儿海岸林二八Ochrosia parviflora Hensl., Cerbera manghas L. ノ2 種ガ冬地二兒ラレル。又 Waren 北方海岸ノ岩 場二八Alyxia lata MGF. ガ見ラレル。

中高地ノ稍乾イ夕所, 例へバ Agathis, Dacrydium, Podocurpus 等ノ針葉樹類ガ現 ハレル海拢 500〜600 米, Dallmann 地方デハAlyxiu (1 種), Parsonsia (2 種), 海 拔 400 米位ノ尾根纷今アル Boemi 地方デハParsonsia (1 種) ヨ探集シタ二過ギ ナカツタガ, 海拔 1900 2400 米ノAngi 湖附近ノ硬葉樹林デ八Parsonsia (1 種), Alyxia (4 種), Clitandropsis (1 種) ヨ探集シタ。

利用方面カラ見ルト本科ノ植物二八格別重要ナモノハナイガ, 藤本トナル Ichnocarpus frutescens R. BR. 八至ル所ノ低地林二堒產シ，ソノ樹皮ノ纎維八强勒デ土人 八之ヨ Pipisa 纎維卜稱シ相當利用シテキル。Momi 附近ノ低地林二多イ Alstonia 
scholaris R. BR. 八熱帶アジア二廣ク分布シ，高サ 30 米以上二モ達スル大喬水デ， ソノ材八室內建築用材トシテ適當シ，樹皮八慢性下孫，赤痢等ノ特效藥卜稱七ラレ Ditain ナル名前デ呼バレテキル。乳液モ多イノデ彈性ゴムモ相當探レルシ又本屬 ノ或儿種類ノ根部カラハ有名ナ輕軟材ガトレルノデ將來之等二就テモ充分做究ノ必 要ガアラウト思ハレル。Cerbera, Ochrosia，Lepiniopsis 等八大材ハナイガ，材質八 緻密デアルカラ室內/建築材卜シテ相當利用出來ルト思ハレル。

最後二今包ノ探集品中特筫ス.ベキ種類二就キ述ベテ見ル。

Clitandropsis crussifolia $\mathrm{K}_{\mathrm{AN}}$. et $\mathrm{H}_{\mathrm{AT}}$. 本屬八從來 2 種 (1 種八南洋群島ペラオ 座) 知ラレテ年タガ, 今包第三番月/種颣习海拢 1900 米附近, Angi 男湖畔ノ森林 內デ探集スルコトガ出來夕。本種ハニューギニア，中高地二廣ク分布スルCl.novoguineensis MIOORE 二近イガ小枝、太ク，葉八著シク愿ク，花序八短カク且密デ，蒸 片ガ著シク長イ點デ容多二區别出來ル。我々，標本八花ガ嚄デ十分ナ解剖ガ出來ナ

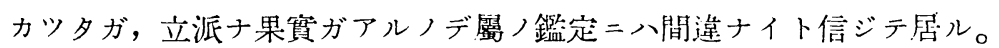

Rauuolfue rostrata IIGF. 本種, type 八Manoluari 附近デ探集サレタモノデ,

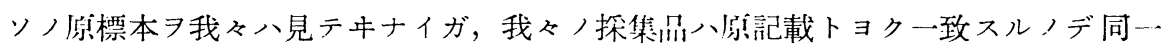
物卜同定シタぶ，只我々ノ採焦品デ八葉八稍薄ク，初メカラ全然無毛(彼八徽毛) ル點ガ罢ナツテキル。原記載、果實ノ標本ニョツタモノデ花ノ記載ガナイカラ果シ テ同一物デアルカドウカ多少ノ疑問ヨ有シテ居ル。

\section{コブスキー氏一つばき科}

ニューギニア探集ノつばき科植物八本科ノ專門家アーノルド樹木園コブスキー氏 ニソノ鑑定习依賴シタ處我々ノ採集品以外ニアーチボルド探險隊ノ探集家ブラス氏 ノ探集品ノ一部 加へテ本報告ガ途ツテ來タノデ本誌二發表スルコトニシタ。我々 ノ探集シタつばき植物八合計 11 種アツテソノ內 4 種八材料不足ノ篇先方二揆ツテ キナカツタ，之等八更二同氏二依賴シ何习改メテ本誌二發表スル豫定デアル。

ニューギニア座ノつばき科デ最モ種類ノ多イノ八ひさかき閩，もくてく屬デたい わんつばき屬八只 2 種知ラレテキルノミデアル。

Gordonia papuana KoBUSKI 本種ハワーレン北方ノ不炭岩ノ山デ，海拔 400 米

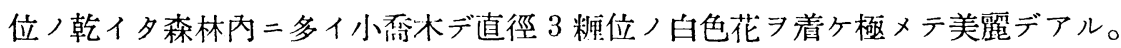

Ternstroemia Kanehirai KoBuskI 本種ハアンギ湖附近ノ尾根秎ノ柾林內二極入 テ普通ナもくてくノ一種デ極メテ特㑕ノアル種類デアル。郎チ小枝及葉八輪生シ, 此 花ノ子房二八 8 個ノ卵子ガアリ, 果實八 8-12 個ノ種子ヨ有シテキル。又花ハもく乙 く類トシテハ極メテ小サク, 雄花〉花瓣八開花中密二重り合ツテ煮沸スルトキハバ ラバラトナルコトナク冠帽狀トナツテ取レル特徽ガアル。亦本種ノ雄花デ八䓵ガ完 全二開イテキル時デサエ花瓣ガ閉鎖シテキルノ八不思議デアル。

T. sphondylophora KOBUSKI 本種八最近英領ニューギニアニ近イフライ河上流 ノ山地デ發見サレタもくとくノ一種デアルガ今包數百哩距ツタアンギ湖附近二發見 シタコト八分布上面白イ。本種ノ葉八非常ニ小サク, 花カ實ガナケレバもくとく類 
ト思ハレナイ程變ツタ種類デアル。

Eurya Kanehirai KoBuskI 本種ハワーレン附近ノ乾イ夕丘陵地ノ疎林內二普通 ナひさかきノ一種デ杜頭ハ 4 個（稀=5個）デロブスキー氏，Penteurya 節二屬ス 儿種類デアル。no. 13028, 13134 八海岸附近ノ崖デ探集シタ關係カ葉ガ小サク，毛ガ 少ク一見別品ノ如ク見へルガコブスキー氏ガ考へル如ク別種デナイト考へル。之= 反シ no. 13141 八同一地方デ探集シタノデアルガ大分樣子ガ異ナリ變種位ノ價值八 アル樣二思ハレルガ材料ガ少イノデ今後ノ研究二俟ツベキモノデアラウ。

Eurya Groffi MerR. 本種八最初比島カラ記載七ラレ, 最近デハニニーギニアニ モ分布スルコトガ刵ツタ。次種卜同樣アンギ湖附近ノ森林內二多イ小喬木デ，次種 ト八只一體二毛ガ深イ點 タルノ價值ガアルカドウカ疑問二思ツテキル。

Eurya tigang Schum. et LAUTB. 本種八最初舊獨領ニユーギニアカラ記載七ラ レタ種類デ最近デハニューギニア各地二分布スルコトガ判ツタ。…臺灣産ノあつ ばひさかきア思八セル樣ナ種類デアル。

Eurya longisepala KoBUSKI 本種ハブラス氏ガニューギニア第...ノ河マンヘヘラ モ一河上流ノ山地ニアル Habbema 湖附近ノ海拔 2350 米ノ森林內デ探集シタモ， デ，最近コブスキー上ハ上記，E.tigang 卜同一物トシテ發表シタガ，今回多數，

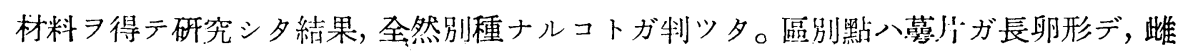

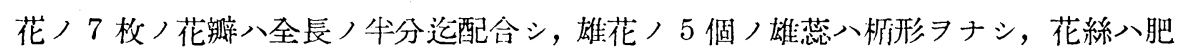
厚シ, 葉ノ毛ノ樣子ヨ罢ニシ，側脈八中胁卜約 45 度ノ角度デ出テキル點等デアル。 利用方面上記ノ種類八總テ小喬木又八灌木デ大材二乏イガ, 硬材產スルもく とく類, 特 = T. Kanehirai KoBUSKI 八量モ相當多イカラ將來利用出來ルトモノ卜 考へル。

（九州帝國大學農學部林學数室） 